\section{Redirect research to control coffee pest}

The coffee-berry borer (Hypothenemus hampei) was accidentally introduced into Brazil in 1913 and later invaded coffee plantations throughout South and Central America, Mexico and the Caribbean. The insect still causes worldwide annual losses of some US $\$ 500$ million, affecting the incomes of more than 20 million coffee-farming families in roughly 80 nations. We contend that a radical change in research direction is called for if the damage inflicted by this pest is to be contained.

The topic has generated more than 1,600 papers, so far with little practical success. This is partly because the insect spends most of its life concealed inside the coffee berry feeding on the seeds, making its management difficult. But it may also be because the focus on developing biological control agents such as fungal entomopathogens and parasitoids is too narrow. The results have been disappointing, and major practical and economic obstacles have prevented their implementation in the field.

Research should instead be aimed at exploring potential attractants and repellents, and at gaining a better understanding of the microbiota associated with the insect.

Francisco Infante, Jeanneth Pérez El Colegio de la Frontera Sur, Tapachula, Chiapas, Mexico. Fernando E. Vega USDA, ARS, Beltsville, Maryland, USA. fernando.vega@ars.usda.gov

\section{Follow the money on climate controversy}

Dan Kahan's analysis of the 'controversy' over climate change is insightful up to a point (Nature 488,$255 ; 2012$ ). But there is one crucial factor that he does not mention: money.

The climate-change controversy has been created by a tiny group of people whose livelihoods depend on it. Oil and its derivatives have made these people extremely rich, so they perpetrate the idea that climate change induced by the use of fossil fuels is a myth to ensure that they stay that way.

The public is prey to a systematic campaign to pollute the science-communication environment (as Kahan so aptly puts it), backed by vast wealth. This campaign is being indirectly abetted by the US Supreme Court, which has declared that political groups may spend limitless amounts of money without identifying themselves. Thomas E. DeCoursey Rush University Medical Center, Chicago, Illinois, USA. tdecours@rush.edu

\section{Green issues are catching on in China}

Your report on the rise of environmental protest in China (Nature 488, 261-262; 2012) is backed up by findings of the Pew Global Attitudes Project, which indicate that $80 \%$ of Chinese people now rate environmental protection as a priority (see go.nature.com/tehbh9).

Landmark cases include spontaneous protests against paraxylene pollution in Xiamen in 2007 and in Dalian in 2011; against garbage incineration at Panyu in 2009; and against waste-water pollution in Qidong earlier this year. So far, people seem more concerned about the impact of local pollutants than about national environmental issues (W. Li, J. Liu and D. Li J. Environ. Mgmt 98, 65-72; 2012).

These protests have raised awareness of environmental pollution among local governments and forced them to address some of the issues.

Environmental protection on a wider scale will demand more concerted action, with strong leadership and organization, and regulations that protect the rights of individuals. It will mean supporting the winners and compensating those who could lose out economically. Qiang Wang, Xi Chen Xinjiang Institute of Ecology and Geography, China. qiangwang7@gmail.com Yi-Chong Xu Griffith University, Australia.

\section{Rationality: Evidence must prevail}

I strongly disagree with Daniel Sarewitz's suggestion that nonmathematicians must use faith to "believe" in the Higgs boson (Nature 488, 431; 2012). The particle's existence is based on hard evidence, not belief.

Evidence is why most ill people visit doctors, rather than sacrifice chickens or visit priests. If we were to abandon evidence, we would soon be in some postmodernist hell. As for faith, the rational thought that underpins science provides us with a system that works. It fosters questioning and makes risky, falsifiable predictions; religion does neither, as it demands blind acceptance of dogma.

Had science and rationality been abandoned in favour of religion, then the stoning of adulterers would be much more common and there would have been many fewer women participating in the Olympic Games. Let's be grown up, rational, accept evidence and put the fairies to bed.

David J. Hosken University of Exeter Cornwall Campus, Penryn, UK.

d.j.hosken@exeter.ac.uk

\section{Rationality: Science is not bad faith}

Perhaps Daniel Sarewitz (Nature 488, 431; 2012) should read more Ludwig Wittgenstein. The philosopher opposed the view of religion as a flawed version of science, lacking in evidence, sophistication or predictive power. Rather, he considered religion a matter of shared practices, observance and ritual that has a special significance to its practitioners. To that extent, there is no meaningful opposition between religion and science: they do not even occupy the same logical space.

Sarewitz's account of what religion can teach science indicates a belief that the two activities are somehow similar and express the same aim. Viewing temples and falling in love can be moving experiences, but they don't reveal a hidden reality whose articulation eludes science.

I am not a believer in the Higgs boson (or related particles) merely because of a cultural artefact. I was born in a country that trusts theoretical physicists more than, say, astrologists (who need no physics for their predictions). That situation has arisen because of the divergent successes of the physical sciences and astrology in understanding the world.

Religion need not be bad science; science is not bad faith. Andy Greenfield Medical Research Council Harwell, UK. a.greenfield@har.mrc.ac.uk

\section{Rationality: Religion defies understanding}

Daniel Sarewitz suggests that we need ways of "understanding our world beyond the scientifically rational" (Nature 488, 431; 2012). Our species has derived many things from its various religions - some fair and noble, others foul and destructive - but understanding is not one of them. Andrew Blight Acorda Therapeutics, Ardsley, New York, USA.

arborlight@gmail.com

\section{CONTRIBUTIONS}

Author guidelines can be found at go.nature.com/ cmchno. 